\title{
THE ROLE OF DENDROCHRONOLOGY IN UNDERSTANDING THE MODERN DECLINE OF WHITEBARK PiNe IN GRAND TETON NATIONAL PARK, WYOMING
}

\author{
KENDRA K. MCLAUCHLAN $\downarrow$ KYLEEN E. KELLY $\uparrow$ KANSAS STATE UNIVERSITY \\ MANHATTAN, KS
}

\begin{abstract}
$\uparrow$ ABSTRACT
Whitebark pine (Pinus albicaulis) is the only pine keystone species found in North America. Although it is considered a keystone species in high elevation ecosystems in the northern Rockies, it occupies a relatively restricted range and its future is uncertain. In modern times, it has experienced a significant decline in population due to pine beetle infestations, blister rust infections, fire suppression, and climate change. Despite the knowledge that the species is severely threatened, little is known about its paleoecology. More specifically, much remains unknown about how the distribution and stability of whitebark pine were affected by past climate change.
\end{abstract}

The purpose of this study is to determine in great temporal and spatial detail the demographics of the current stand of whitebark pine trees in the watershed surrounding an unnamed, high-altitude pond (known informally as Whitebark Pine Moraine Pond) located approximately 3.06 miles NW of Jenny Lake in Grand Teton National Park (GTNP). The main objectives of this study are:

1.) To obtain the precise GPS locations of the current stand of whitebark pine trees in the watershed to generate a GIS map detailing their locations.

2.) To obtain increment cores of a subset of the trees in the watershed to estimate age and date of establishment for the current stand of whitebark pines, with particular attention to fire history.
3.) To analyze ring widths from core samples to identify climatic indicators that may influence the regeneration and survival of whitebark pine.

\section{$\uparrow \quad$ INTRODUCTION}

Whitebark pine is a long-lived, moderately shade tolerant species found only at high elevation sites occurring in subalpine ecosystems of the Northern Rocky and Cascade Mountains in the United States (Keane and Parsons 2010). In modern times, the most pressing mortality event in subalpine forests of western North America is occurring in whitebark pine (Millar et al. 2012). In addition to biotic factors such as blister rust and pine beetles, there is some preliminary data indicating increased mortality in whitebark pine due to a warming climate (Bower and Aitken 2008). Historical climate data, based on records from NOAA dating from 1949-2012, indicates that the average yearly temperature in the Greater Yellowstone Ecosystem is increasing, while the yearly amounts of both overall precipitation and snowfall are decreasing. A significant portion (10-15\%) of these rapidly vanishing trees are found in the Greater Yellowstone Area (GYA) and GTNP (Figure 1). Of these $10-15 \%$ of whitebark pine trees, it has been suggested that only a slight increase in global atmospheric temperature $\left(4.5^{\circ} \mathrm{C}\right)$ would completely remove whitebark pine from the GYA and GTNP ecosystems (Schrag et al. 2008).

Whitebark pine is considered to be a keystone species of the particular ecological niche it occupies in the United States for three reasons. First, more than one hundred animal species, including the endangered 
grizzly bear (Ursus arctos horribilis), depend on its high-energy seeds for survival (Felicetti et al. 2003). If whitebark pine should vanish from its niche, endangered species would be forced to lower elevations in search of food, thus increasing the potential for contact with humans and human-caused casualties. Second, the presence of whitebark pine in subalpine ecosystems helps to slow the melting of accumulated snow, resulting in reduced flooding occurrences. And third, by slowing the melt of snow, whitebark pine provides a high quality source of water to plants and animals during the summer melting season (Keane and Parsons, 2010).

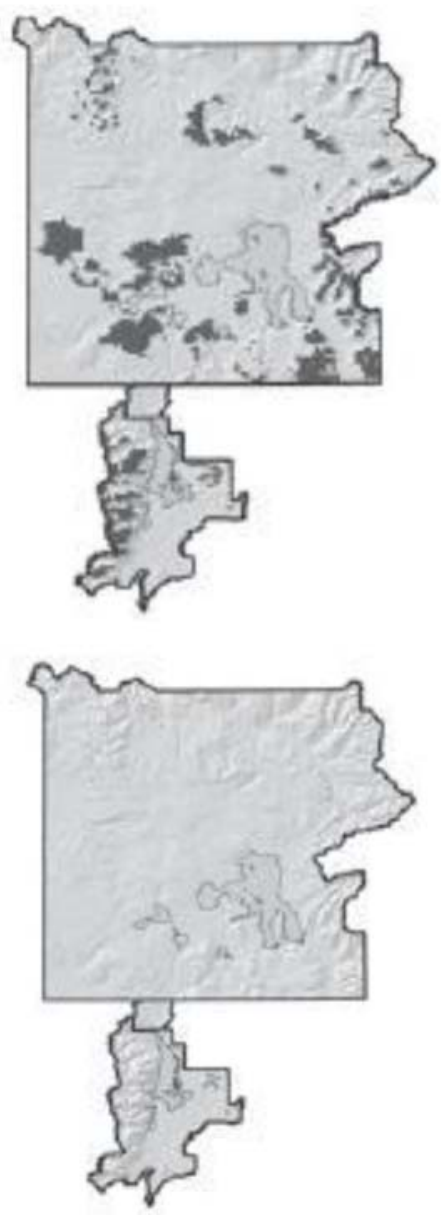

Figure 1. The current range and distribution of whitebark pine in GTNP and GYA (top), and the predicted range and distribution of whitebark pine in GTNP and GYA given a projected 4.5C temperature increase (bottom). From Schrag et al. 2008.

In addition to its importance as a keystone species, whitebark pine also has value as a recreational resource. Whitebark pine has many aesthetic qualities that make it a potential attraction to park visitors. Tree species that thrive at high altitudes generally have unusual morphological characteristics resulting from the harsh conditions provided by high altitude conditions. One of the most striking characteristics of high altitude species, including whitebark pine, is the twisted formations of trunks and branches. Additionally, whitebark pine has value as a recreational resource because communities tend to form very open, park-like forests ideal for adventurous hikers (Keane and Parsons 2010). Lastly, whitebark pine forests offer value as a recreational resource for avid birdwatchers. Whitebark pine is the only species of pine in North America that does not disperse its seeds utilizing wind. Rather, whitebark pine relies on a mutualistic relationship with a bird - the Clark's Nutcracker - to disperse its seeds. In the late summer and fall, Clark's Nutcrackers harvest seeds from the whitebark pinecones and carry them up to ten kilometers away and bury them (Tomback 1982). The nutcrackers will eventually return for the seed stocks, but those seeds left unclaimed will eventually begin to germinate (Tomback et al. 2001). This mutualistic relationship with the Clark's Nutcracker would provide avid birders the opportunity to see this highaltitude bird in action during the summer and fall months, that, without the presence of whitebark pine, they would likely never see.

Demographics about the current stand gained from this study will provide two key pieces of evidence. First, results from the proposed study will provide an indication of how the current stand of whitebark pine trees came to exist in the watershed by providing both estimated ages and dates of establishment. Should the results indicate that all whitebark pine trees in the watershed are roughly the same age, it can be inferred that they grew as the result of a stand-replacing fire, thus indicating the importance of fires to the survival of the species. There is some preliminary data indicating that standreplacing wildfires are important for establishing whitebark pines (Peterson 1999). If trees are vastly different in age, this would indicate that fire plays a less significant role in survival than past research suggests.

Second, results from analyzing tree ring widths would provide information as to how whitebark pine responded to past climate change. It is known that during times of climate change, zones of vegetation tend to respond by shifting their ranges (Whitlock 1993). Upper treeline in mixed spruce-fir communities in the Rocky Mountains has been shown to be especially dynamic to climate change (Elliott 2011). However, nothing is known specifically about how these past changes in climate altered the range or 
stability of whitebark pine in the United States. Given the narrow elevational zone occupied by whitepark pine, this proposed research would be valuable in forming conservation plans because one of the main concerns associated with the disappearance of whitebark pine is range shift due to climate. The most effective way to establish a solution for the current crisis is to understand how the species, and ecosystem as a whole, responded to climate change in the past.

Much of the high-elevation wildlife and scenery in Grand Teton National Park exist only because of whitebark pine's role as a keystone species. Understanding how climate change has affected, and continues to affect, this threatened and disappearing species will help park conservationists develop new strategies for maintaining and restoring the current stands of whitebark pine trees.

\section{$\uparrow \quad$ STUDY AREA}

Fire, vegetation, and dendrochronological histories were examined at a small, un-named subalpine lake (known informally as Whitebark Moraine Pond; $43.79^{\circ} \mathrm{N}, 110.110 .79^{\circ} \mathrm{W}$; elevation $2800 \mathrm{~m}$; Figure 2) and the surrounding watershed in Grand Teton National Park, WY, USA (Jones 2013). The lake and surrounding watershed are located at treeline in the uppermost reaches of Paintbrush Canyon, approximately $5 \mathrm{~km} \mathrm{NW}$ of Jenny Lake. The lake has a maximum depth of $4 \mathrm{~m}$ and a watershed of 0.76 ha. The watershed contains no inlet or outlet systems, and the majority of hydrologic input is provided by summer snowmelt.

Whitebark Moraine Pond, a morainedammed lake, was produced by late Pinedale glacial activity (Jones 2013, Pierce 2003). Moraine-dammed lakes generally form when glacial meltwater collects behind terminal moraine debris as a glacier retreats (Richardson and Reynolds 2000). Whitebark Moraine Pond resulted from the retreat of a Pinedale glacier which reached its maximum extent in Grand Teton National Park approximately 9000 yr BP (Marston et al. 2005). As the Pinedale glacier retreated, resulting meltwater became trapped by terminal moraine debris and was prevented from flowing downslope, resulting in the formation of a dammed lake. The terminal moraine and rocky debris are still present in the southeast section of the study site.

The modern vegetational ecosystem of the study area can be characterized as a subalpine conifer forest. Canopy species dominate the watershed and consist primarily of whitebark pine (Pinus albicaulis), subalpine fir (Abies lasiocarpa), and Engelmann spruce (Picea engelmannii). Shade produced by the dense canopy results in a sparse understory including a small number of grasses and forbs. However, likely due to environmental constraints, vegetation approaching watershed boundaries (i.e. higher in elevation) is almost exclusively composed of whitebark pine.

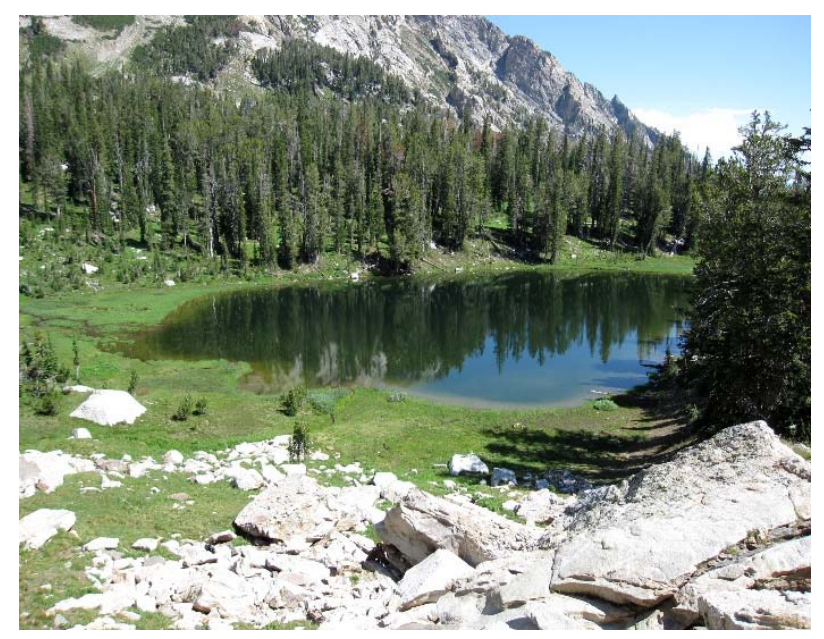

Figure 2. Photo of the study site location showing vegetation of the watershed. Photo courtesy of Dr. Sarah Spaulding.

Typical of most high-elevation ecosystems, soils in the watershed generally lack well-developed horizons (Tomback et al. 2001). The lack of soil profile development is primarily caused by a combination of steep slopes and high rates of eolian erosion (Weaver 2001). As a result of poor development, soils in the watershed have a relatively low water-holding capacity; it has been estimated that approximately $35-60 \%$ of all annual precipitation becomes surface runoff in high elevation watersheds, though soil drought is uncommon (Tomback et al. $2001)$. Soils in the watershed contain a large portion of organic matter ( $>20 \%$; Jones 2013) due to the high annual production of conifers and slow decomposition characteristic of cold climates.

Annual growing season (May-July) precipitation at the site from 1895-2012 averaged 310 $\mathrm{mm}$, and showed no significant trends during the time period. Annual growing season maximum temperature averaged $14.68{ }^{\circ} \mathrm{C}$ for the same time period, and annual growing season minimum temperature averaged $-1.94{ }^{\circ} \mathrm{C}$. The average annual range in temperature for the time period was $12.74{ }^{\circ} \mathrm{C}$ and has been steadily decreasing since the mid 1980's. This decrease in annual temperature range is attributed to an increase in average growing season minimum temperatures. Average growing season minimum 
temperature has increased rather significantly since the mid 1980 's, increasing a total of $6.12^{\circ} \mathrm{C}$. More specifically, annual July minimum temperatures have increased $8.89^{\circ} \mathrm{C}$ since the 1980 's.

\section{METHODS}

Where necessary, project methods have been approved by the respective permitting authority or oversight committee.

\section{GPS locations to determine demography}

The location of each whitebark pine in the watershed was recorded using a high-quality GPS unit. The latitude and longitude coordinates of each tree location were recorded and stored in the unit. All recorded coordinates were ultimately used to create a map depicting the exact location of each whitebark pine in the watershed as it relates to other features such as the pond. This map was generated using the latest available version of ArcGIS software. A map of whitebark pine locations would be valuable from a conservation standpoint because such maps seldom exist because whitebark pine has never been used as a timber resource.

\section{Increment cores}

From the total number of whitebark pines in the watershed, twenty were selected to core to establish ages and dates of establishment. Cores from the selected subset of trees were taken using standard dendro-chronological techniques with a $5.15 \mathrm{~mm}$ diameter increment bore $30 \mathrm{~cm}$ above the soil surface (Elliott 2011). Diameter at breast height (dbh) was also recorded. Once the cores were in a laboratory setting, they were sanded and scanned, and rings on each individual core were counted to establish chronologies, using crossdating protocols and software. Pith estimators and age-to-coring-height equations were applied as in Elliott (2011). The dates and spatial patterns of establishment were then used to determine if the current stand grew in response to a stand-replacing fire or if each tree grew independently.

\section{Response to modern climate}

Tree ring widths of each core were measured and recorded. An analysis of tree ring widths provided important information about the magnitude of climate change events experienced by each tree, as well as how climate change events impacted the growth and stability of each tree on a local scale. Methods generally followed those of a larger study of climate and local scale factors on upper treeline in the Rocky Mountains (Elliott 2012). Because climate stations are rare at higher elevations in the Rocky Mountains, Precipitation-elevation Regressions on Independent Slopes Model (PRISM) data were used for the study site (Daly et al. 2008). This climate analysis allows for the comparison between climate conditions in the past and the current climates in order to predict the response of the current stand of whitebark pine.

\section{$\downarrow \quad$ PRELIMINARY RESUltS}

\section{Demography of current stand}

The average date of establishment for the current stand of whitebark pine is 1751 C.E., however, individual dates of establishment range from 1324 C.E. to 1919 C.E. Of the 16 trees that were cored to the center, $75 \%$ were established between 1600 C.E. and 1800 C.E. (Figure 3A). With the exclusion of the oldest individual, $\mathrm{dbh}$ is inversely related to date of establishment $\left(\mathrm{R}^{2}=0.62\right)$; that is, older individuals are typically larger than younger individuals (Figure 3B). Transect data indicate that only $14 \%$ of the current stand is composed of whitebark pine, with subalpine fir and Engelmann spruce occupying $81 \%$ and 5\%, respectively. All new growth within the survey area consisted of subalpine fir.

\section{Ring widths and modern climate}

Average yearly ring widths ranged from 1.23 $\mathrm{mm}$ in 1950 to $0.60 \mathrm{~mm}$ in 2011 for the period of available climate data (1895-2012) (Figure 4A). A breakpoint analysis confirmed the presence of change point at 1949 ( \pm 4.5 years $)$ and further indicated that average ring widths increased until 1949, and then began to decline to their current widths.

Average July minimum temperature (Tmin) was identified as the most statistically significant variable affecting annual ring widths $(\mathrm{p}<0.001)$ (Figure 4B). Other temperature and precipitation variables had no significant effect on the growth of whitebark pine at this site. Until 1991 ( \pm 2 years), average July Tmin values experienced no significant variation and remained relatively constant through time. A maximum value of $37.38 \mathrm{~F}$ was reached in 1945, with a spread in data of 8.07 F. After 1991, however, average July Tmin values exhibited more variability and increased to temperatures higher than any other time during the record. Values reached a maximum in 2011 with an average July Tmin of 45.7 F with a spread of 13.34 F from 1991-2011. 

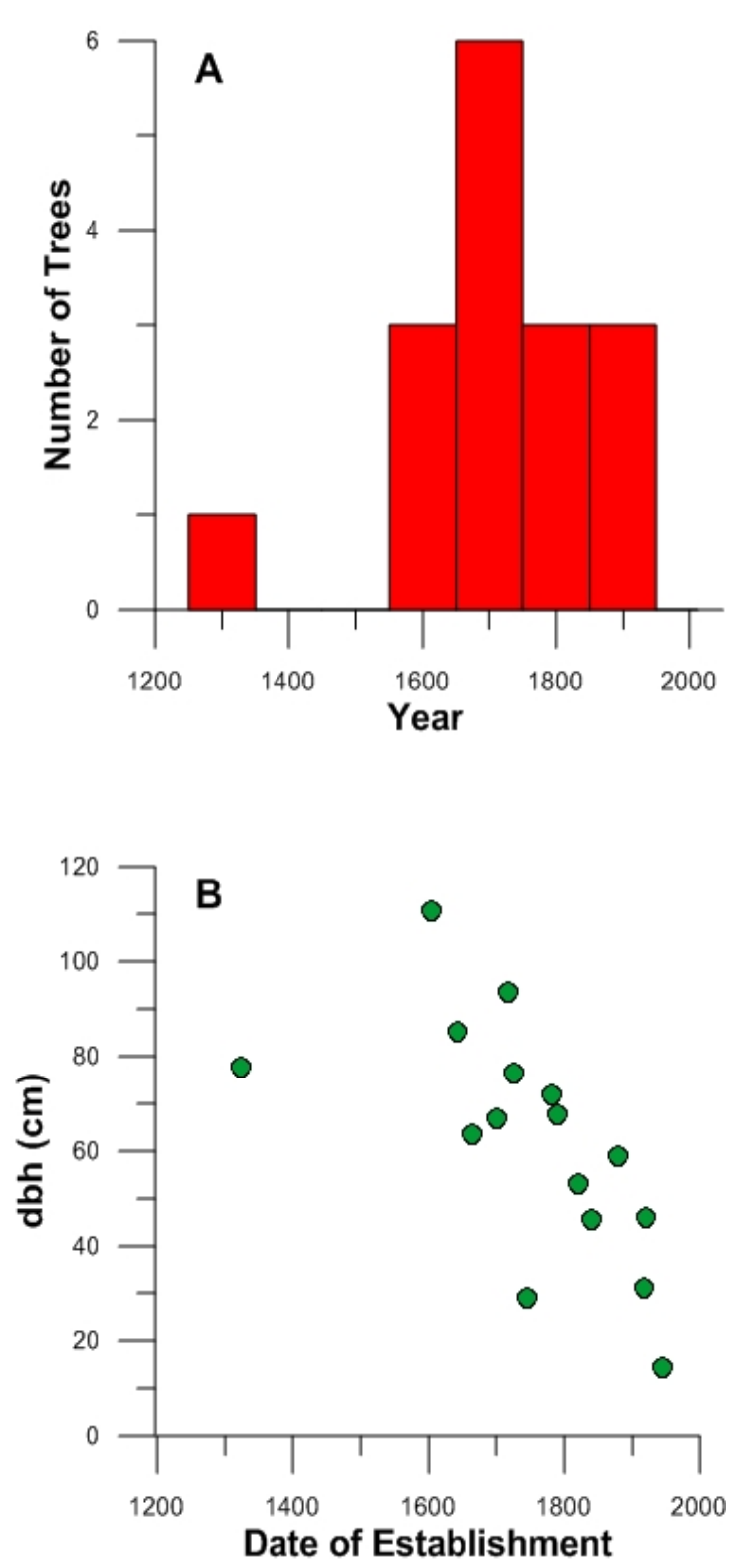

Figure 3. (A) Trends in estimated dates of establishment for all cored trees. (B) Relationship between dates of establishment and measured dbh values.

Average July Tmin values were plotted against average annual ring widths to determine the effect of climate on tree growth (Figure 4C). Analyses indicated that average July Tmin values were a significant $(p<0.001)$ predictor of whitebark pine growth. The resulting relationship between the two variables reveals that the modern decline in whitebark pine growth at the study site can be attributed to increasing July minimum temperatures.
Increasing July minimum temperatures have aided in the displacement of whitebark pine by subalpine fir. The initial onset of declining ring widths around 1949 may have been triggered by an unknown ecological event which subsequently increased the stand's sensitivity to later temperature changes beginning in 1991, thereby amplifying its effect on the population. Abies and Picea, competitors of whitebark pine, are better adapted to survive in warmer climates than whitebark pine. While July minimum temperatures were discovered as the most significant variable at this site, Perkins and Swetnam (1996) observed a significant inverse relationship between ring widths and May temperatures in the Sawtooth-Salman River region of Idaho. This discrepancy in climate variables may be caused by the geographic difference in site locations. In both cases, increased growing season temperatures have resulted in altered subalpine conifer communities by allowing warm temperature-adapted species to invade the niche normally occupied by whitebark pine. Because subalpine fir tends to grow much faster than whitebark pine, it acts as a competitor for resources and ultimately restricts the growth of whitebark pine through out-shading.

\section{MANAGEMENT IMPLICATIONS}

Our results indicate that whitebark pine populations are decreasing in GTNP as a direct result of warming July temperatures. This modern decline of whitebark pine poses several management and conservation challenges. The fundamental risk associated with the loss of this species centers around whitebark pine's role as a keystone species. Because the endangered grizzly bear depends so heavily on whitebark pine seeds for survival, the disappearance of whitebark pine has the potential to increase humanbear mortality events as bears are forced to lower elevations in search of alternative food sources.

The central challenge associated with mitigating this modern decline of whitebark pine is that climate change (the main driver of this decline) is not an environmental problem with a simple solution. Climate change is a global phenomenon acting on a long timescale. Because this driver of whitebark pine decline is not easily managed, the best management option will be to focus on more locally-driven processes contributing to the decline, such as fire suppression. 

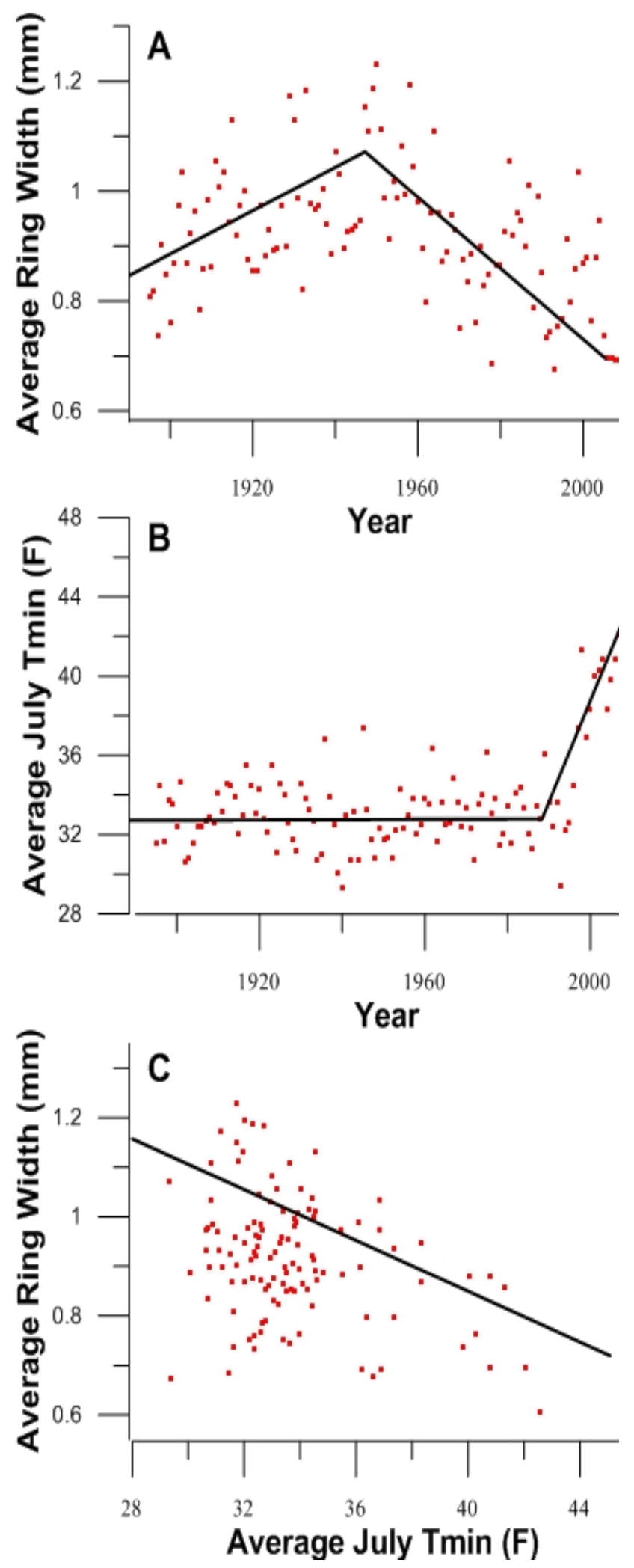

Figure 4. (A) Average ring widths by year. (B) Average July minimum temperatures by year. (C) Relationship between ring widths and July minimum temperatures $(p<0.001)$.

\section{ACKNOWLEDGEMENTS}

In addition to support from the UW-NPS Research Station, this project has received key funding from the Department of Geography at Kansas State University and the Association for Women Geoscientists.

\section{LITERATURE CITED}

Bower, A. D., and S. N. Aitken. 2008. Ecological genetics and seed transfer guidelines for Pinus albicaulis (Pinaceae). American Journal of Botany 95(1): 66-76.

Daly, C., M. Halbleib, J. I. Smith, W. P. Gibson, M. K. Doggett, G. H. Taylor, and P. P. Pasteris. 2008. Physiographically sensitive mapping of climatological temperature and precipitation across the conterminous United States. International Journal of Climatology 28(15): 2031-2064.

Elliott, G. P. 2011. Influences of 20th-century warming at the upper tree line contingent on local-scale interactions: Evidence from a latitudinal gradient in the Rocky Mountains, USA. Global Ecology and Biogeography 20(1): 46-57.

Elliott, G. P. 2012. Extrinsic regime shifts drive abrupt changes in regeneration dynamics at upper treeline in the Rocky Mountains, USA. Ecology 93(7): 1614-1625.

Felicetti, L. A., C. C. Schwartz, R. O. Rye, M.A. Haroldson, K. A. Gunther, D. L. Phillips, and C. T. Robbins. 2003. Use of sulfur and nitrogen stable isotopes to determine the importance of whitebark pine nuts to Yellowstone grizzly bears. Canadian Journal of Zoology 81(5): 763-770.

Jones, E. V. 2013. A Spectroscopic Approach for Inferring Charcoal Concentrations and Fire History from Lacustrine Sediments. M.Sc. Thesis. University of Alberta, Canada.

Keane, R. E., and R. A. Parsons. 2010. Restoring whitebark pine forests of the northern Rocky Mountains, USA. Ecological Restoration 28(1): 56-70.

Millar, C. I., R. D. Westfall, D. L. Delany, M. J. Bokach, A. L. Flint, and L. E. Flint. 2012. Forest mortality in high-elevation whitebark pine (Pinus albicaulis) forests of eastern California, USA: Influence of environmental context, bark beetles, climatic water deficit, and warming. Canadian Journal of Forest Research 42(4): 749-765. 
Mohatt, K. R., C. L. Cripps, and M. Lavin. 2008. Ectomycorrhizal fungi of whitebark pine (a tree in peril) revealed by sporocarps and molecular analysis of mycorrhizae from treeline forests in the Greater Yellowstone Ecosystem. Botany 86(1): 14-25.

Pierce, K. L. 2003. Pleistocene glaciations of the Rocky Mountains. Development in Quaternary Science 1: 63-76.

Richardson, S. D., and J. M. Reynolds. 2000. An overview of glacial hazards in the Himalayas. Quaternary International 65: 3147.

Schrag, A. M., A. G. Bunn, and L. J. Graumlich. 2008. Influence of bioclimatic variables on tree-line conifer distribution in the Greater Yellowstone Ecosystem: Implications for species of conservation concern. Journal of Biogeography 35(4): 698-710.
Tomback, D. F. 1982. Dispersal of whitebark pine seeds by Clark's Nutcracker: A mutualism hypothesis. Journal of Animal Ecology 51: 451-467.

Tomback, D. F., and P. Achuff. 2010. Blister rust and western forest biodiversity: Ecology, values and outlook for white pines. Forest Pathology 40: $186-225$.

Tomback, D. F., A. J. Anderies, K. S. Carsey, M. L. Powell, and S. Mellmann-Brown. 2001. Delayed seed germination in whitebark pine and regeneration patterns following the Yellowstone fires. Ecology 82: 2587-2600.

Weaver, T. 2001. Whitebark pine and its environment. Pages 41-73 In: D. F. Tomback, S. F. Arno, and R. E. Keane (eds.). Whitebark Pine Communities: Ecology and Restoration. Island Press, Washington DC.

Whitlock, C. 1993. Postglacial vegetation and climate of Grand Teton and southern Yellowstone National Parks. Ecological Monographs 63: 173-198. 